\title{
Optimization of Operating Conditions for the Production of Enhanced Antifungal Metabolites from Streptomonospora arabica VSM 25 by Full Factorial Design
}

\author{
Ushakiranmayi Managamuri ${ }^{1}$, Muvva Vijayalakshmi ${ }^{1 *}$, Sudhakar Poda ${ }^{2}$, Venkat Siva Rama Krishna Ganduri ${ }^{2,3}$, Satish Babu Rajulapati ${ }^{4}$ \\ 'Department of Botany and Microbiology, Acharya Nagarjuna University, Nagarjuna nagar, Guntur-52510, Andhra Pradesh, INDIA. \\ 2Department of Biotechnology, Acharya Nagarjuna University, Nagarjuna nagar, Guntur-52510, Andhra Pradesh, INDIA. \\ ${ }^{3}$ Department of Biotechnology, K L University, Vaddeswaram, Guntur, Andhra Pradesh, INDIA. \\ ${ }^{4}$ Department of Biotechnology, National Institute of Technology, Warangal, Telangana, INDIA.
}

\begin{abstract}
Objectives: To execute the influence of the physico-chemical variables on the production of the bioactive metabolites by Streptomonospra arabica VSM-25 using Response Surface Methodology. Materials and Methods: An actinobacterium strain isolated from the deep sea marine sediment samples was identified as Streptomonospra arabica VSM-25 by conventional and molecular approaches. RSM was employed to study the impact of five variables, viz. incubation time, $\mathrm{pH}$, temperature, galactose and peptone concentrations on the production of antifungal metabolites by VSM-25. Growth related production formation kinetics and substrate utilization in batch system was analysed using mathematical and unstructured kinetic models. Results: Statistical study showed that the incubation time, $\mathrm{pH}$, Temperature, Concentration of galactose and peptone has a significant effect $(p<0.0001)$ on the bioactive metabolite production at their individual and interactive level. A second order polynomial model provided a satisfied fit for experimental data with regard to the production of antifungal metabolites. Maximum antimycotic activity was achieved at incubation time (11 days), $\mathrm{pH}(8)$, temperature $\left(30^{\circ} \mathrm{C}\right)$, galactose concentration $(2 \%)$ and peptone concentration (1\%). Unstructured mathematical kinetic model was developed and estimated kinetic parameters also exhibited good approximation in terms of model fitting and regression analysis. Conclusion: To the best of our knowledge this is the first report on the production of anti fungal metabolites from $S$. arabica using RSM and kinetic modelling
\end{abstract}

studies which firmly support the application of RSM and kinetic modelling for optimization. The study may find potential application in rapid screening and production of novel drug molecules from unexploited natural sources.

Key words: Streptomonospora arabica, Antimycotic Activity, Optimization, Kinetic Modelling, Response Surface Methodology, Bioactive Metabolites. Key message: The outcome of the present study strongly supports, RSM based optimization of fermentation conditions. The optimization of environmental parameters and cultural conditions plays a crucial role in the enhanced antimycotic activity. This study contributes towards scale-up of production of antifungal agents by Streptomonospora arabica VSM-25. The unstructured model provided a better approximation of kinetic profiles of bioactive metabolite production by the strain in shake-flask fermentations.

Correspondence :

Prof. M. Vijayalakshmi, Department of Botany and Microbiology, Acharya Nagarjuna University, Nagarjuna nagar, Guntur-52510, Andhra Pradesh, INDIA.

Phone: 9440870026

Email: profmvl08@gmail.com

DOI: 10.5530/jyp.2017.9.80

\section{INTRODUCTION}

Biotechnologically and economically crucial priceless prokaryotes are taken into consideration as natural source for clinically active antibiotics. They hold a prominent position due to their ability to produce secondary metabolites with complex structures and potent biological activities. ${ }^{1}$ Marine resource has not been explored completely and is a hub for isolation of rare actinomycetes with potency to produce novel bioactive compounds. $^{2}$ The biosynthesis of the natural products involves the optimization studies for their production that can be engineered with systemic design for suitable physiological conditions and supplementary nutrients. Media constituents and the cultural parameters play important role in antimicrobial agent's production. ${ }^{3}$

Traditional optimization includes the study of one-factor-at-a-time which is time consuming and tiresome. Further, the interactive effects of the variables are not known which lead to misleading conclusions, hence it is very critical to establish the optimum conditions that yield highest quantities of the bioactive metabolites with functional properties retained. RSM is a statistical protocol to materialize and systematize the process variables for optimizing the bioactive metabolite production. ${ }^{4,5}$ RSM was implemented to optimize the process parameters in multi factorial design experiments ${ }^{6}$ for economizing the number of experimental trials, hence it is extensively applied ${ }^{7}$ for theoretical process of optimization $^{8}$ and interpretation of experiments. ${ }^{9}$

Bioengineers rely on fermentation kinetic information to design and control microbial processes using mathematical models. Of these, structured models consider cell structure, function and composition aspects; while unstructured models consider only total cellular concentration. However, later ones are proven to be accurate in describing many fermentation processes in a wide range of experimental conditions and media. ${ }^{10-15}$ To describe the system in better way, evaluation of assumed unstructured models with experimental statistics by considering the whole cell mass to explain the biological system and that in turn elucidates the fermentation profiles of bio product microbial processes. ${ }^{16-17}$

In this study, the main objectives were isolation and identification of the actinobacterial strain, optimization of different variables that influence the maximal production of bioactive metabolites using RSM and determine kinetic parameters of bioactive metabolite production from S.arabica VSM 25.

This is an open access article distributed under the terms of the Creative Commons Attribution-NonCommercial-ShareAlike 4.0 License, which allows others to remix, tweak, and build upon the work non-commercially, as long as the author is credited and the new creations are licensed under the identical terms. 


\section{MATERIALS AND METHODS}

\section{Isolation}

The deep sea sediment samples were collected at different depths of the Bay of Bengal of coastal Andhra Pradesh, India, were transported to the laboratory in sterile bags and air dried at room temperature. The samples were subjected to pre-treatment with sodium dodecyl sulphate $(0.05 \%)$ and yeast extract $(5 \%) .{ }^{18}$ One gram of pre-treated sample was suspended in $100 \mathrm{ml}$ of sterile distilled water and serial dilutions were prepared down to $10^{-4}$ dilution was plated on Marine Agar medium (containing $0.5 \%$ peptic digest of animal tissue, $0.1 \%$ yeast extract, $0.01 \%$ ferric citrate, $1.94 \%$ sodium chloride, $0.88 \%$ magnesium chloride, $0.32 \%$ sodium sulphate, $0.18 \%$ calcium chloride, $0.05 \%$ potassium chloride, $0.016 \%$ sodium bicarbonate, $0.08 \%$ potassium bromide, $0.003 \%$ strontium chloride, $0.002 \%$ boric acid, $0.0004 \%$ sodium silicate, $0.0002 \%$ sodium fluorate, $0.0001 \%$ ammonium nitrate, $0.0008 \%$ disodium phosphate and $2 \% \operatorname{agar}(\mathrm{pH} 8))$ supplemented with nalidixic acid $\left(50 \mu \mathrm{gml}^{-1}\right)$ and nystatin $\left(50 \mu \mathrm{gml}^{-1}\right)$. The inoculated plates were incubated at $30^{\circ} \mathrm{C}$ for 4 weeks.

\section{Identification}

The actinomycetes strain VSM-25 isolated from the deep sea marine sediment samples was identified as S.arabica VSM-25 by cultural, morphological, physiological and biochemical studies along with $16 \mathrm{~S}$ ribosomal DNA (rDNA) analysis (GenBank: KU507598). The strain was maintained on ISP-2 agar medium at $4^{\circ} \mathrm{C}$.

\section{Experimental design}

RSM is a group of mathematical and statistical evaluation that enables the assessment of the alliance existing between the experimental factors and their response. To achieve significant model, prior information of the process and process variables under study is required. RSM was executed to analyse the optimum levels of the five variables (Time, $\mathrm{pH}$, Temperature, concentrations of Galactose and Peptone) for the production of bioactive metabolites by VSM 25 and its effect against responses was measured in terms of anti-mycotic activity (zone of inhibition in $\mathrm{mm}$ ), by disk diffusion method. The selection of the variable under study followed the one-factor-at-a-time approach. The coded and uncoded individual variables used in the study are listed (Table 1). Range of variables and central points were selected based on the preliminary experimental information (Supplementary Table 1). The experiments were designed with application of $2^{5}$ full factorial central composite design for five variables that consists 32 factorial factors, 10 axial factors and 8 replicates. The 8 replicates at centre points used for each categorical variable which includes a total of 50 experiments (Supplementary Table 1), were calculated from the subsequent equation (1). ${ }^{19}$

$$
N=2^{n}+2 n+n_{c}=2^{5}+2 \times 5+8=50
$$

A second order polynomial equation was used to express the responses as a characteristic of the independent variables as follows: ${ }^{20}$

$$
Y=\beta_{0}+\sum_{i=1}^{n} \beta_{i} X_{i}+\left(\sum_{i=1}^{n} \beta_{i i} X_{i}\right)^{2}+\sum_{i=1}^{n-1} \sum_{j=i+1}^{n} \beta_{i j} X_{i} X_{j}
$$

$Y=$ Predicted response, $\beta_{0}=$ intercept coefficient, $\beta_{\mathrm{i}}=$ linear coefficient, $\beta_{\mathrm{ij}}=$ interaction coefficients, $\beta_{\mathrm{ii}}=$ quadratic coefficients, $X_{\mathrm{i}}$ and $X_{\mathrm{j}}=$ coded values of the five additive variables. $3 \mathrm{D}$ plots were generated by varying two variables with the experimental range with the other variable constant at the central point. Fractional factorial design with centre points are augmented with a group of "star points" that allows estimation of curvature.

Regression and graphical analysis of the data obtained was executed using Design-Expert 7. By optimizing the second-order polynomial equation and analysing the $3 \mathrm{D}$ plots, ${ }^{21}$ the optimum combinations of individual variables were determined. Statistical model analysis was performed by ANOVA which include Fisher's $F$-test, its probability $P(F)$, correlation coefficient $R$ and determination coefficient $R^{2}$ which measures the goodness of the model fit. Adequate precision have been taken into consideration. The quadratic model for each variable was represented as $3 \mathrm{D}$ plots.

\section{Unstructured Kinetic Model}

The proliferation of VSM 25 with restricting carbon substrates impacts the antifungal metabolite production. Many researchers have used mathematical and unstructured kinetic models to define the substrate utilization and growth-related production kinetics in a batch system. ${ }^{22}$

An unstructured kinetic model was developed to study the performance of Nocardiopsis litoralis VSM-8 ${ }^{23}$ and the similar model is used, here, to predict the kinetics of S.arabica VSM 25 fermentation for its growth, substrate utilization and antifungal metabolite production. The kinetic parameters viz., specific cell growth rate $(\mu \max ), \mathrm{d}^{-1}$, unique bioactive metabolite production rate, $\mathrm{d}^{-1}$, maximum specific cell growth rate, $\mathrm{d}^{-1}$, etc., were estimated. ${ }^{24}$

\section{RESULTS}

\section{Central Composite Design}

50 experiments were executed in randomized run order. Supplementary Table 1 explains the experimental design matrix which determines the impact of the five variables on the production of the bioactive metabolite by VSM 25 and its effect on the five responses (Zone of inhibition in $\mathrm{mm})$. The suggested sequential model analyse the sum of squares and lack of fit tests for the best outcome quadratic model, for all the five responses (Table 2).

\section{Response surface analysis of bioactive metabolite production}

The highest antimycotic activity of the bioactive metabolite produced by VSM 25 was recorded when the strain was grown in a medium containing $2 \%$ galactose, $1 \%$ peptone with $\mathrm{pH} 8$ incubated at $30^{\circ} \mathrm{C}$ for 11 days. The maximum zone of inhibition against all the five responses was found to be $20.8 \mathrm{~mm}$ (Aspergillus niger), $18.9 \mathrm{~mm}$ (Aspergillus flavus), $20 \mathrm{~mm}$ (Fusarium oxysporum), 18mm (Fusarium solani) and $19 \mathrm{~mm}$ (Candida albicans)

RSM regression analysis was performed to fit the experimental data of each response through second-order polynomial equation. The model is found to be significant with the $p$-value $(<0.0001)$ for all the five responses. The lower the $p$ value the more significant is the model. Using the experimental data for the bioactive metabolite production, the polynomial model was regressed by only considering significant terms (Table 3).

Table 1: Uncoded and coded levels of variables used in the RSM design

\begin{tabular}{clccc}
\hline \multirow{2}{*}{ Symbols } & Independent Variables & \multicolumn{3}{c}{ Coded levels } \\
\cline { 3 - 5 } & & -1 (Low) & 0 (Middle) & +1 (High) \\
\hline $\mathrm{A}$ & $\begin{array}{l}\text { Time of Incubation } \\
(\text { days })\end{array}$ & 10 & 11 & 12 \\
$\mathrm{~B}$ & $\mathrm{pH}$ & 7.0 & 8.0 & 9.0 \\
$\mathrm{C}$ & Temperature $\left({ }^{\circ} \mathrm{C}\right)$ & 25.0 & 30.0 & 35.0 \\
$\mathrm{D}$ & $\begin{array}{l}\text { Concentration of } \\
\text { Galactose }(\% \mathrm{w} / \mathrm{v})\end{array}$ & 1.0 & 2.0 & 3.0 \\
$\mathrm{E}$ & $\begin{array}{l}\text { Concentration of } \\
\text { Peptone }(\% \mathrm{w} / \mathrm{v})\end{array}$ & 0.5 & 1.0 & 1.5 \\
\hline
\end{tabular}


Managamuri et al.: Antifungal Metabolite Production By Streptomonospora arabica VSM 25 Using RSM

Table 2: Sequential model fitting for all the responses (in terms of inhibition zone from the bioactive metabolite production)

\begin{tabular}{|c|c|c|c|c|c|}
\hline Model parameter & Aspergillus niger & $\begin{array}{c}\text { Aspergillus } \\
\text { flavus }\end{array}$ & Fusarium oxysporum & Fusarium solani & Candida albicans \\
\hline \multicolumn{6}{|c|}{ Sequential model sum of squares- Quadratic vs 2FI (suggested) } \\
\hline Sum of squares & 104.97 & 78.21 & 84.44 & 55.92 & 68.85 \\
\hline d.f. ${ }^{a}$ & 5 & 5 & 5 & 5 & 5 \\
\hline Mean square & 20.99 & 15.64 & 16.89 & 11.18 & 13.77 \\
\hline F-value & 210.04 & 513.86 & 136.86 & 255.14 & 2827.45 \\
\hline $\begin{array}{c}\text { p-value } \\
(\text { Prob > F })\end{array}$ & $<0.0001$ & $<0.0001$ & $<0.0001$ & $<0.0001$ & $<0.0001$ \\
\hline \multicolumn{6}{|c|}{ Lack of fit tests- Quadratic (suggested) } \\
\hline Sum of squares & 2.19 & 0.88 & 2.70 & 1.27 & 0.14 \\
\hline d.f. ${ }^{\text {a }}$ & 22 & 22 & 22 & 22 & 22 \\
\hline Mean square & $7.535 \times 10^{-3}$ & 0.040 & 0.12 & 0.058 & $6.42 \times 10^{-3}$ \\
\hline F-value & 0.98 & --- & 0.98 & --- & --- \\
\hline $\begin{array}{c}\text { p-value } \\
(\text { Prob }>F)\end{array}$ & 0.5534 & --- & 0.5534 & --- & --- \\
\hline
\end{tabular}

d.f.- degrees of freedom

Table 3: Second-order quadratic model equations and regression coefficients (\%) of responses

\begin{tabular}{cl}
\hline \multicolumn{1}{c}{ Response } & \multicolumn{1}{c}{ Second-order quadratic model equation (in coded factors) } \\
\hline \multirow{3}{*}{ Aspergillus niger } & $\mathrm{Y}=-113.10310+12.93121 \mathrm{~A}+9.37724 \mathrm{~B}+1.40159 \mathrm{C}+2.86931 \mathrm{D}+5.73862 \mathrm{E}+0.000000 \mathrm{AB}+0.000000 \mathrm{AC}+0.000000 \mathrm{AD}$ \\
& $+0.000000 \mathrm{AE}+0.000000 \mathrm{BC}+0.000000 \mathrm{BD}+0.000000 \mathrm{BE}+0.000000 \mathrm{CD}+0.000000 \mathrm{CE}+0.000000 \mathrm{DE}-0.59233 \mathrm{~A}^{2}-0.59233 \mathrm{~B}^{2}-$ \\
& $0.023693 \mathrm{C}^{2}-0.79233 \mathrm{D}^{2}-3.16931 \mathrm{E}^{2}$ \\
& $\mathrm{Y}=-70.94483+7.78966 \mathrm{~A}+7.33793 \mathrm{~B}+0.84069 \mathrm{C}+3.23448 \mathrm{D}+6.06897 \mathrm{E}+0.000000 \mathrm{AB}+0.000000 \mathrm{AC}+0.000000 \mathrm{AD}+0.000000 \mathrm{AE}$ \\
& $+0.000000 \mathrm{BC}+0.000000 \mathrm{BD}+0.000000 \mathrm{BE}+0.000000 \mathrm{CD}+0.000000 \mathrm{CE}+0.000000 \mathrm{DE}-0.35862 \mathrm{~A}^{2}-0.45862 \mathrm{~B}^{2}-0.014345 \mathrm{C}^{2}-$ \\
& $0.85862 \mathrm{D}^{2}-3.43448 \mathrm{E}^{2}$ \\
& $\mathrm{Y}=-86.80345+8.75690 \mathrm{~A}+8.04138 \mathrm{~B}+1.42621 \mathrm{C}+2.61034 \mathrm{D}+6.22069 \mathrm{E}+0.000000 \mathrm{AB}+0.000000 \mathrm{AC}+0.000000 \mathrm{AD}+0.000000 \mathrm{AE}$ \\
& $+0.000000 \mathrm{BC}+0.000000 \mathrm{BD}+0.000000 \mathrm{BE}+0.000000 \mathrm{CD}+0.000000 \mathrm{CE}+0.000000 \mathrm{DE}-0.40259 \mathrm{~A}^{2}-0.50259 \mathrm{~B}^{2}-0.024103 \mathrm{C}^{2}-$ \\
& $0.70259 \mathrm{D}^{2}-3.21034 \mathrm{E}^{2}$ \\
& $\mathrm{Y}=-69.77379+8.04759 \mathrm{~A}+5.82552 \mathrm{~B}+1.12883 \mathrm{C}+2.48138 \mathrm{D}+3.96276 \mathrm{E}+0.000000 \mathrm{AB}+0.000000 \mathrm{AC}+0.000000 \mathrm{AD}+0.000000 \mathrm{AE}$ \\
& $+0.000000 \mathrm{BC}+0.000000 \mathrm{BD}+0.000000 \mathrm{BE}+0.000000 \mathrm{CD}+0.000000 \mathrm{CE}+0.000000 \mathrm{DE}-0.37034 \mathrm{~A}^{2}-0.37034 \mathrm{~B}^{2}-0.018814 \mathrm{C}^{2}-$ \\
& $0.67034 \mathrm{D}^{2}-2.28138 \mathrm{E}^{2}$ \\
& $\mathrm{Y} 5=-82.25793+7.21586 \mathrm{~A}+11.47517 \mathrm{~B}+0.75628 \mathrm{C}+2.59379 \mathrm{D}+4.58759 \mathrm{E}+0.000000 \mathrm{AB}+0.000000 \mathrm{AC}+0.000000 \mathrm{AD}+0.000000 \mathrm{AE}$ \\
& $+0.000000 \mathrm{BC}+0.000000 \mathrm{BD}+0.000000 \mathrm{BE}+0.000000 \mathrm{CD}+0.000000 \mathrm{CE}+0.000000 \mathrm{DE}-0.32345 \mathrm{~A}^{2}-0.72345 \mathrm{~B}^{2}-0.012938 \mathrm{C}^{2}$ \\
& $-0.72345 \mathrm{D}^{2}-2.49379 \mathrm{E}^{2}$
\end{tabular}

$Y=$ response, $A=$ Incubation time (days), $B=\mathrm{pH}, C=$ Temperature $\left({ }^{\circ} \mathrm{C}\right), D=$ Galactose concentration $(\% \mathrm{w} / \mathrm{v}), E=$ Peptone concentration $(\% \mathrm{w} / \mathrm{v})$

\section{Model adequacy checking}

Results of ANOVA used to test the model adequacy at confidence level of $99 \%$ were given in Table 4 . Coefficient of determination $\left(R^{2}\right)$ indicates the proportion of the total variability of the model explained and suggests that model to be a good fit. The $R^{2}$ value of the model was found to be $>0.9$ and reflected to be a very good fit between the observed and the predicted response values (Table 4$)$. The values of the adjusted $R^{2}(>0.9)$ for model is high which indicate high significance of the model. Signal to noise ratio is measured by adequate precession and values greater than four are desirable. Coefficient variation is the standard deviation expressed in terms of percentage of the mean and should be less than $10 \%{ }^{25}$ The model showed statistical insignificant Lack-of-fit (Table 4) which indicate the model to be good fit. The experimental values are in close agreement with the predicted values. Which imply that model for each response fits the experimental data adequately.

\section{Variables and interaction effects}

$3 \mathrm{D}$ plots of RSM illustrate the interactive effects of the variables on the five responses with two varying parameters at a fixed value of the third operating parameter (Figure 1, 2, 3, 4, 5). The evaluation of the plots show that all the five parameters recorded a positive effect at the beginning and attained a maximum production and further increase in the range of values and concentration showed a negative effect on the production of the bioactive metabolites by VSM- 25 .

\section{Optimum operating conditions and corresponding results}

Optimum incubation time, $\mathrm{pH}$, temperature and concentration of galactose and peptone was found to be 11 days, $30^{\circ} \mathrm{C}, \mathrm{pH} 8$ and concentration of galactose $2 \%$ and peptone $1 \%$ (Figure 6). The recorded zones of inhibi- 
Table 4: Analysis of ANOVA variance to test the adequacy of the model

\begin{tabular}{cccccc}
\hline Statistics & \multicolumn{5}{c}{ Response } \\
\cline { 2 - 6 } & A.niger & A.flavus & F.oxysporum & F.solani & C.albicans \\
\hline $\mathrm{R}^{2}$ & 0.9748 & 0.9898 & 0.9604 & 0.9796 & 0.9981 \\
Adj-R & 0.9574 & 0.9828 & 0.9331 & 0.9655 & 0.9968 \\
Pred- R & 0.9447 & 0.9742 & 0.9131 & 0.9483 & 0.9952 \\
Adequate Precession & 20.800 & 32.662 & 15.431 & 23.228 & 77.767 \\
CV \% & 1.74 & 1.04 & 2.01 & 1.30 & 0.41 \\
\hline
\end{tabular}

Table 5: Estimated kinetic parameters using L, LILP, LIMLP model equations

\begin{tabular}{|c|c|c|c|c|c|}
\hline $\begin{array}{c}\text { Kinetic } \\
\text { Parameters }\end{array}$ & A.niger & A.flavus & F.oxysporum & F.solani & C.albicans \\
\hline \multicolumn{6}{|c|}{ Logistics incorporated Modified Luedeking-Piret (LIMLP) Model parameters } \\
\hline$\gamma($ g.S/g.X) & & & 23.356 & & \\
\hline $\mathrm{R}^{2}$ & & & 0.9493 & & \\
\hline$\eta($ g.S $/($ g.X.d) $)$ & & & 1.8421 & & \\
\hline \multicolumn{6}{|c|}{ Logistics incorporated Luedeking-Piret (LILP) Model parameters } \\
\hline$\alpha(\mathrm{mm} / \mathrm{g} . \mathrm{X})$ & 85.179 & 59.965 & 77.075 & 70.157 & 83.546 \\
\hline $\mathrm{R}^{2}$ & 0.956 & 0.9 & 0.9683 & 0.962 & 0.9641 \\
\hline$\beta(\mathrm{mm} /(\mathrm{g} . \mathrm{X} . \mathrm{d}))$ & 7.5188 & 11.2782 & 7.5188 & 7.5188 & 7.5188 \\
\hline \multicolumn{6}{|c|}{ Logistic (L) Model Parameters } \\
\hline$\mu_{\max }\left(d^{-1}\right)$ & & & 0.7642 & & \\
\hline $\mathrm{R}^{2}$ & & & 0.9654 & & \\
\hline$X_{0}(g / L)$ & & & 0.005 & & \\
\hline$X_{\max }(\mathrm{g} / \mathrm{L})$ & & & 0.266 & & \\
\hline
\end{tabular}

Table 6: Comparison of zones of inhibition $(\mathrm{mm})$ from shake-flask experiments and from model

\begin{tabular}{cccccc}
\hline $\begin{array}{c}\text { Maximum } \\
\text { Zone of } \\
\text { Inhibition }(\mathrm{mm})\end{array}$ & A.niger & A.flavus & F.oxysporium & F. solani & C.albicans \\
\hline Experimental & 29 & 29 & 28 & 26 & 29 \\
Model fitted & 33.6 & 32.91 & 31.05 & 29.72 & 33.17 \\
\hline
\end{tabular}

tion ( $\mathrm{mm}$ ) against the five responses was found to be $20.8 \mathrm{~mm}$ for Aspergillus niger, $18.9 \mathrm{~mm}$ for Aspergillus flavus, $20 \mathrm{~mm}$ for Fusarium oxysporum, $18 \mathrm{~mm}$ for Fusarium solani and $19 \mathrm{~mm}$ for Candida albicans. All the controlling parameters were found to be within the range, whereas the production of the bioactive metabolite by VSM-25 was found to be high.

\section{Estimation of kinetic parameters}

The profiles of S. arabica VSM 25 growth, restraining substrate utilization results obtained from shake flask experiments and model kinetics have been compared in Figure 7. The assessment of experimental versus model predicted inhibition zones of produced bioactive metabolite on media, inoculated with A. niger, A. flavus, F. oxysporum, F. solani and C. albicans strains over the time are shown in Figure 8. A very good fit observed between model predicted and experimental results. In this study, Microsoft Excel Solver 2010 was used to fit the experimental data with unstructured Logistic models, nonlinear regression using leastsquare method and estimated biokinetic parameters are tabulated in Table 5. It also indicates determination coefficient $\left(\mathrm{R}^{2}\right)$ values obtained through fitting Logistic (L), Logistic Incorporated Leudeking-Piret
(LILP) and Logistic Incorporated Modified Leudeking-Piret (LIMLP) models to the experimental data were found to be high, thus revealing correct precision of the models.

The L model parameters $\mu_{\max }, X_{0}, X$ max and LILP model parameters $\alpha$ and $\beta$, were estimated from shake-flask data and a higher $\alpha$ values than $\beta$ showed that antifungal metabolite production by VSM 25 is more growth related than non-growth associated in shake flask. The simulated LIMLP model parameters, $\gamma$ and $\eta$, are also in desirable agreement with the experimental data, confirms the chosen model is more appropriate to predict the substrate consumption pattern in bioactive metabolite production by VSM $25 .{ }^{26}$ Further, Table 6 shows similarity between experimental and model predicted zones of inhibition from agar diffusion tests. Hence, the unstructured models provided a better approximation of kinetic profiles of bioactive metabolite production by S.arabica VSM 25 in submerged shake flask fermentations.

\section{DISCUSSION}

RSM based experimental approach with central point was used to determine the significant parameters and their interactions that influence 


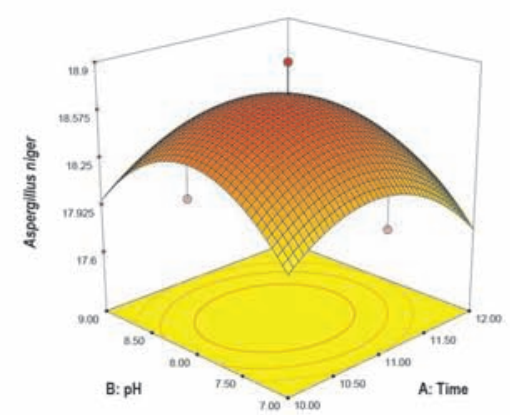

$\mathrm{AB}$

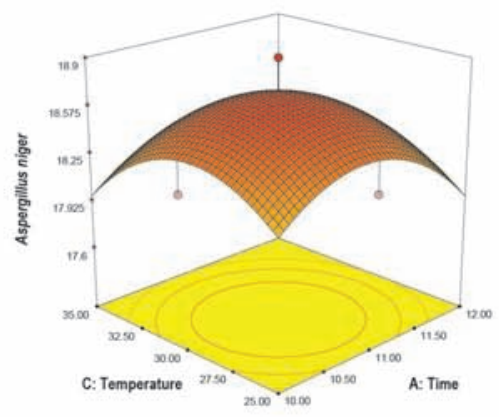

AC
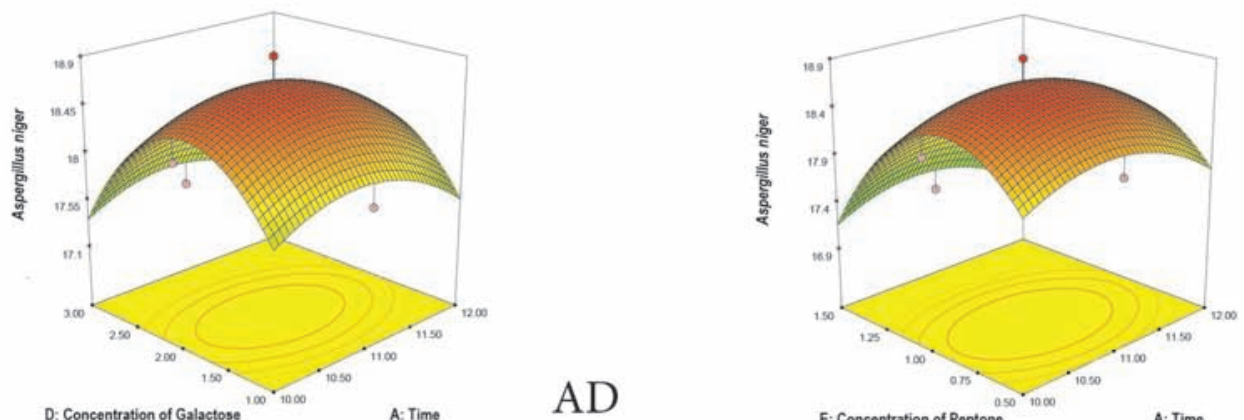

$\mathrm{AE}$

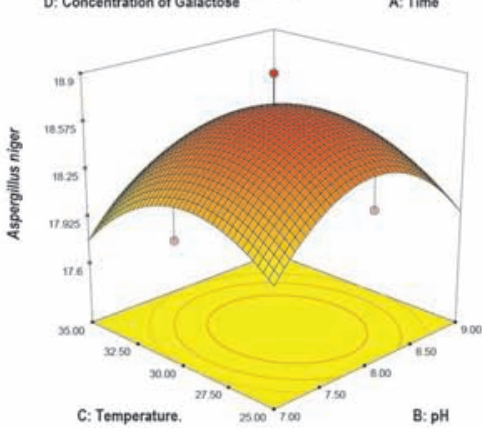

$\mathrm{AD}$

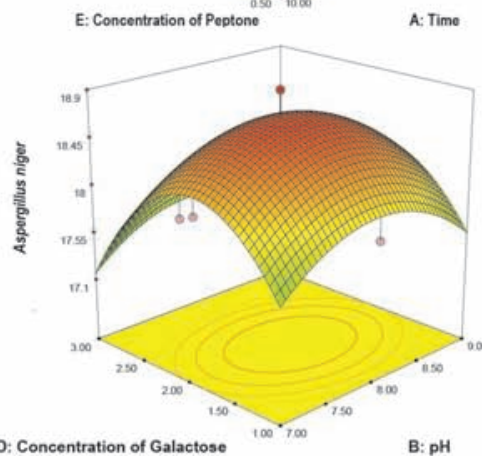

BD
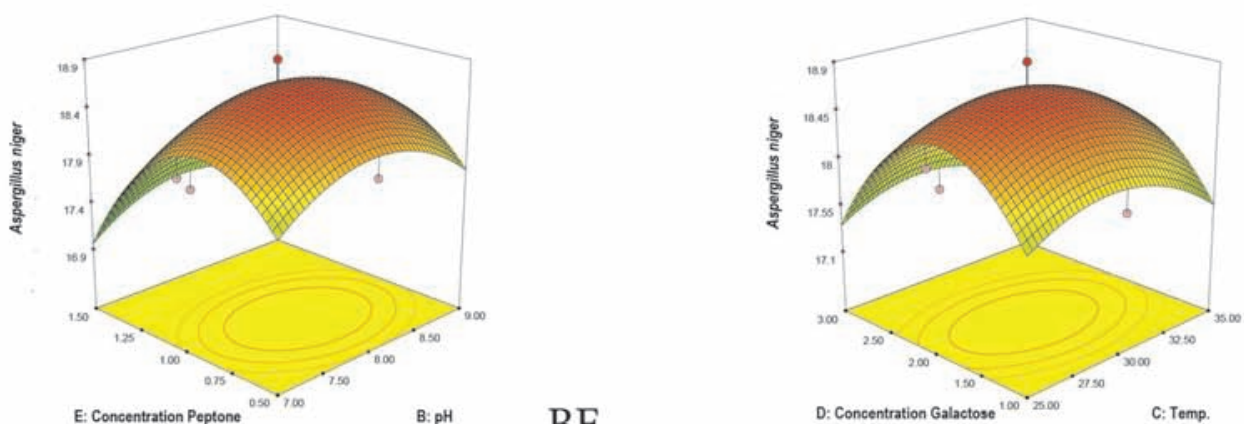

CD

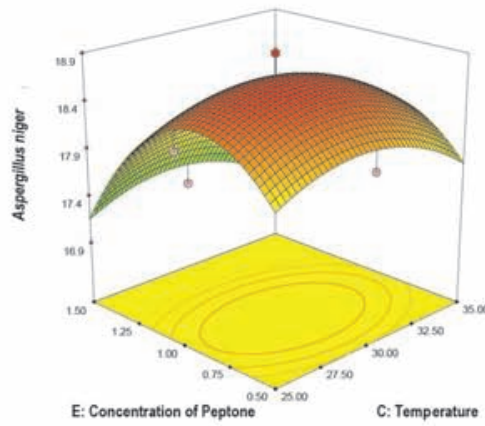

BE

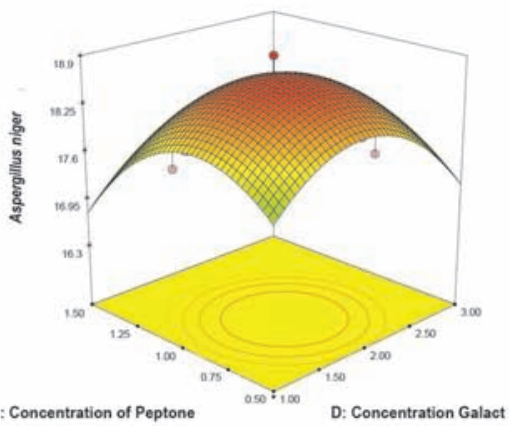

Figure 1: 3D plots showing interactive effects of selective variables on zone of Inhibition ( $\mathrm{mm}$ ) of the bioactive compound production by VSM 25 against Aspergillus niger. 


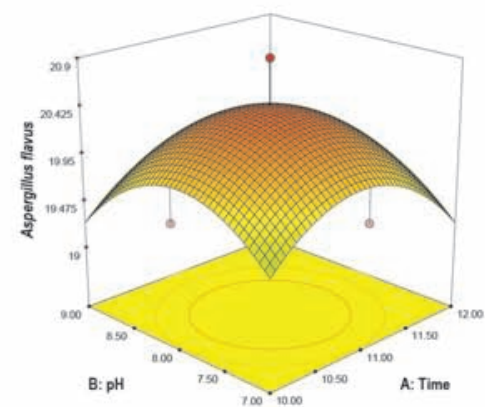

$\mathrm{AB}$
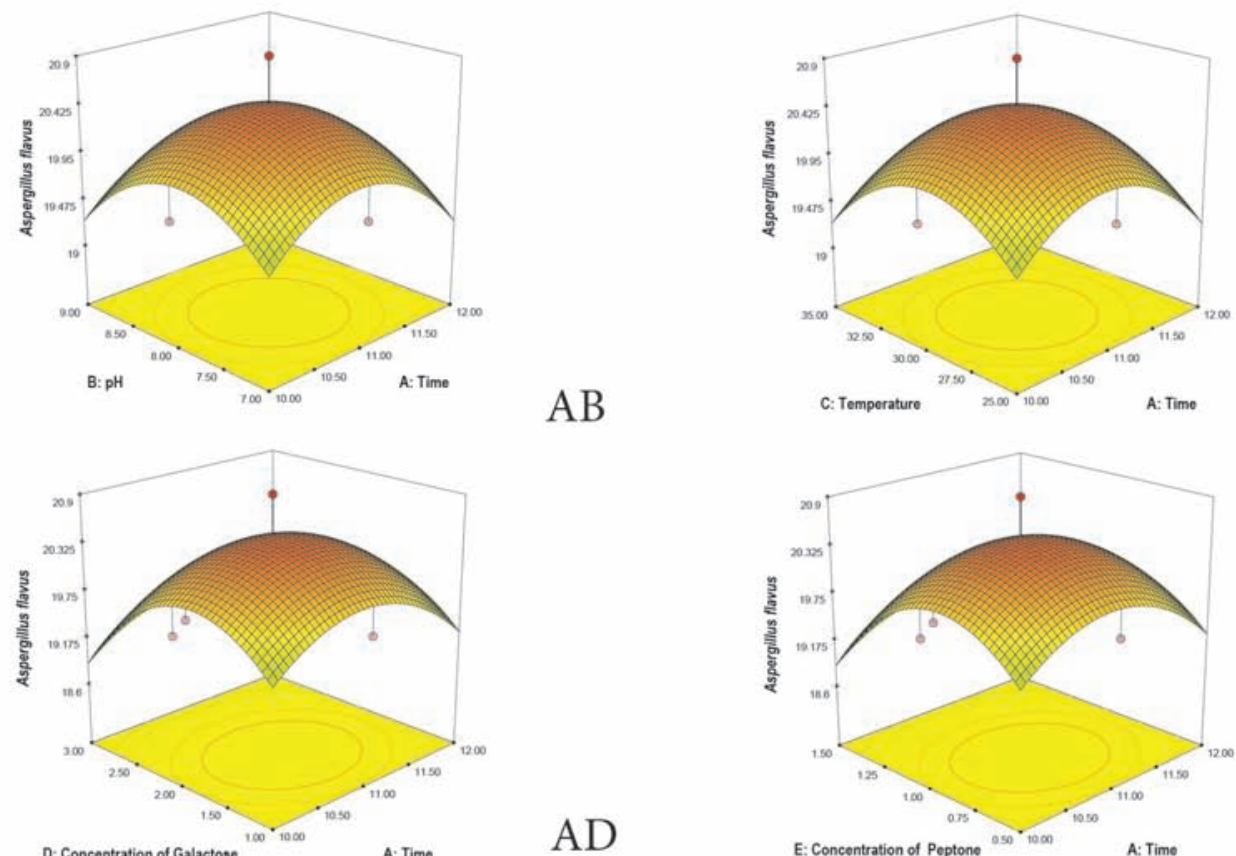

$\mathrm{AC}$

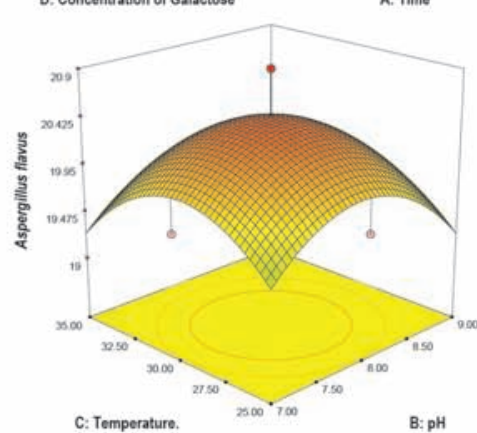

$\mathrm{AD}$

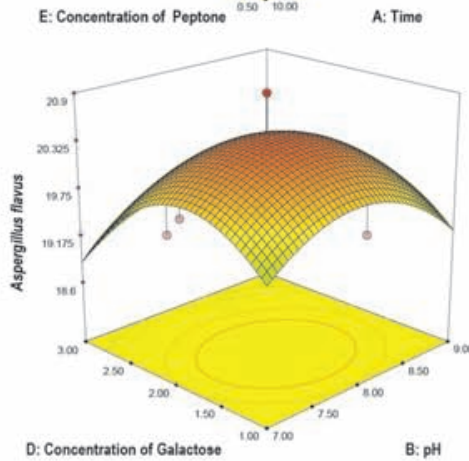

$\mathrm{AE}$
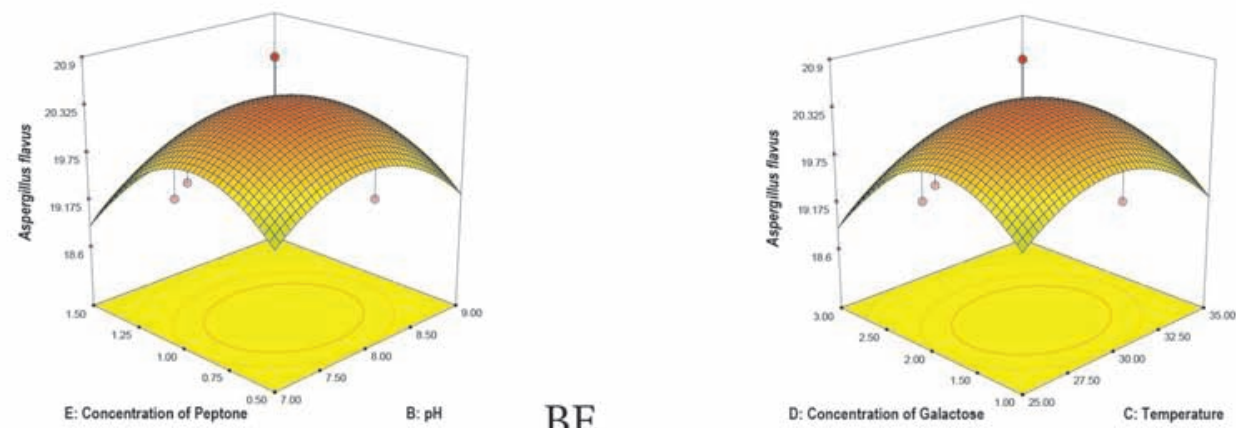

$\mathrm{BD}$

$\mathrm{BE}$

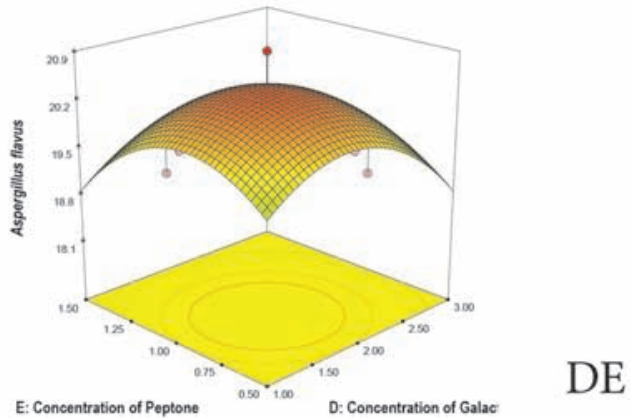

Figure 2: 3D plots showing interactive effects of selective variables on zone of Inhibition $(\mathrm{mm})$ of the bioactive compound production by VSM 25 against Aspergillus flavus. 

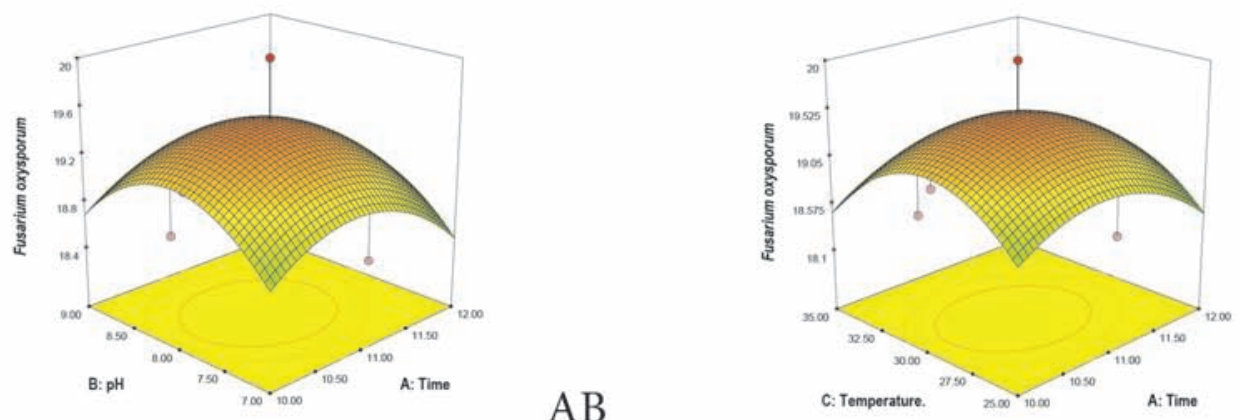

AC

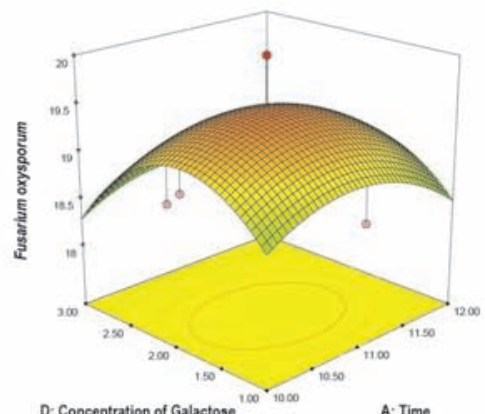

AB

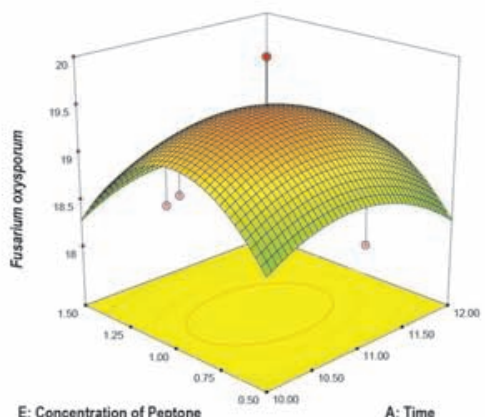

AE

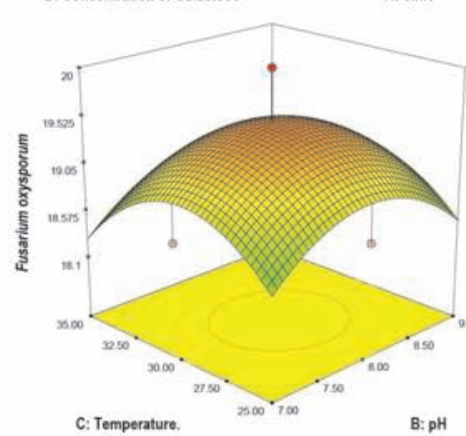

AD

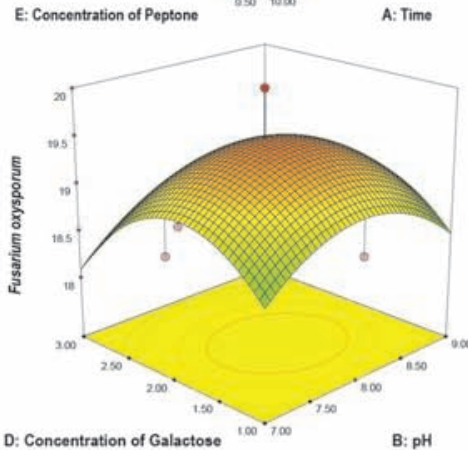

BD
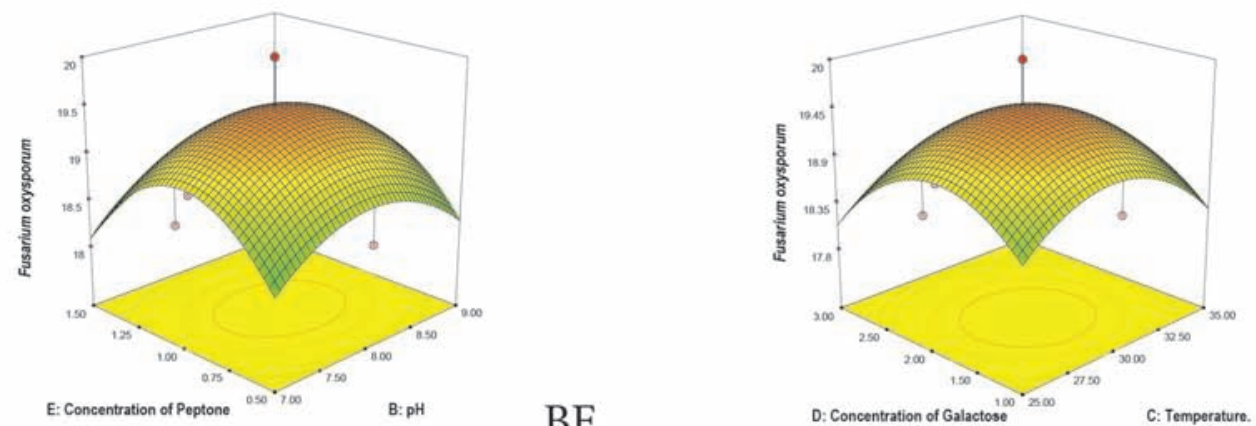

CD

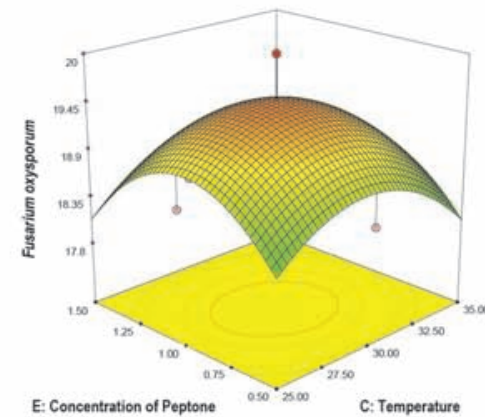

BE

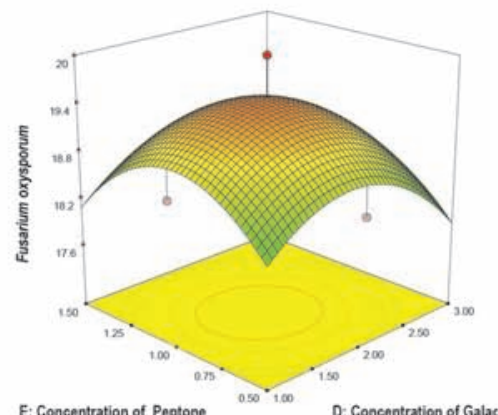

DE

Figure 3: 3D plots showing interactive effects of selective variables on zone of Inhibition $(\mathrm{mm})$ of the bioactive compound production by VSM 25 against Fusarium oxysporum 


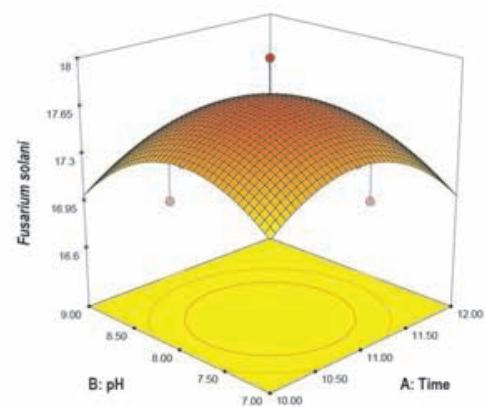

$\mathrm{AB}$
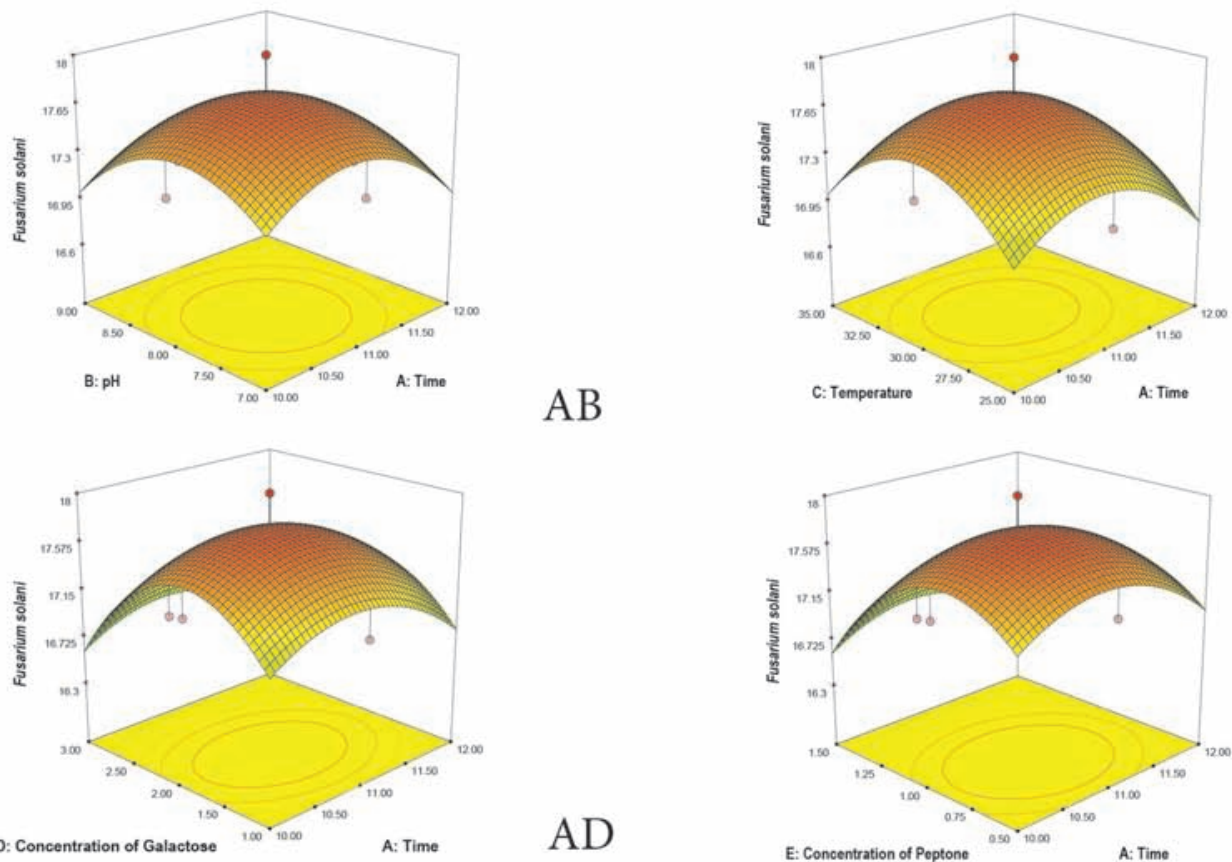

$\mathrm{AC}$

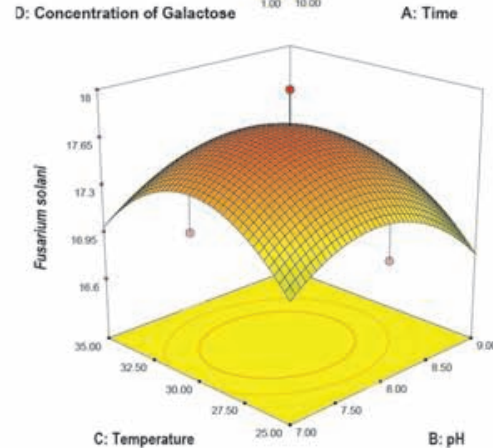

$\mathrm{AD}$

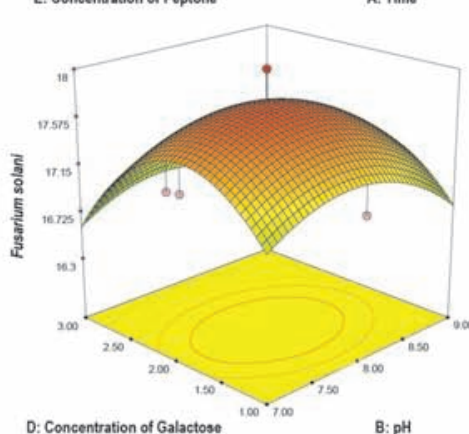

$\mathrm{AE}$
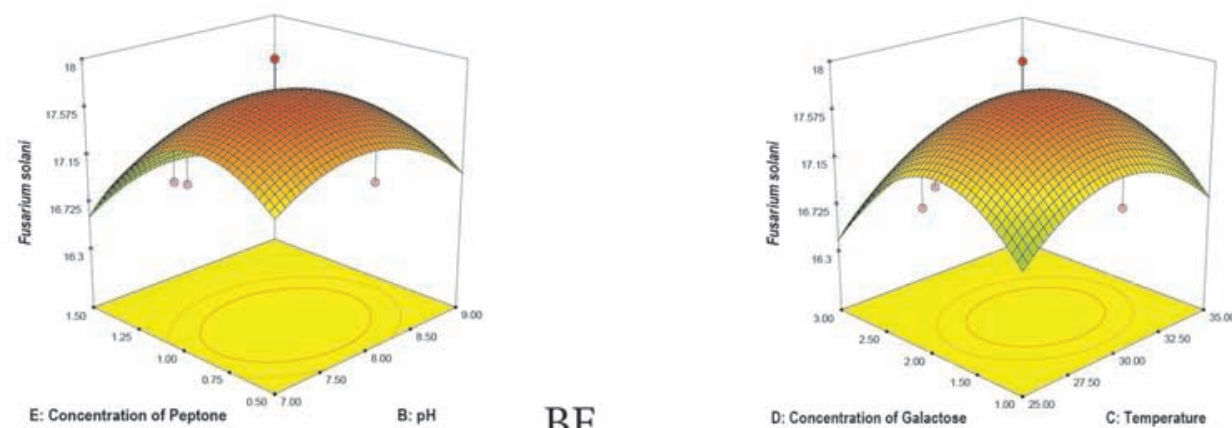

$\mathrm{BD}$

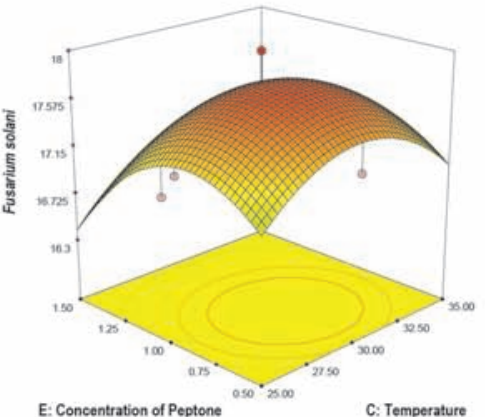

$\mathrm{BE}$

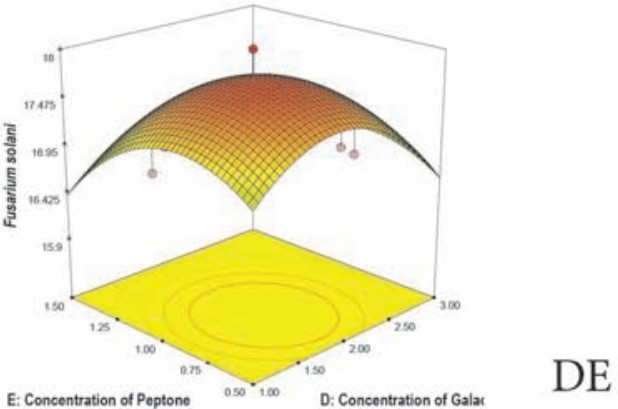

Figure 4: 3D plots showing interactive effects of selective variables on zone of Inhibition $(\mathrm{mm})$ of the bioactive compound production by VSM 25 against Fusarium solani. 

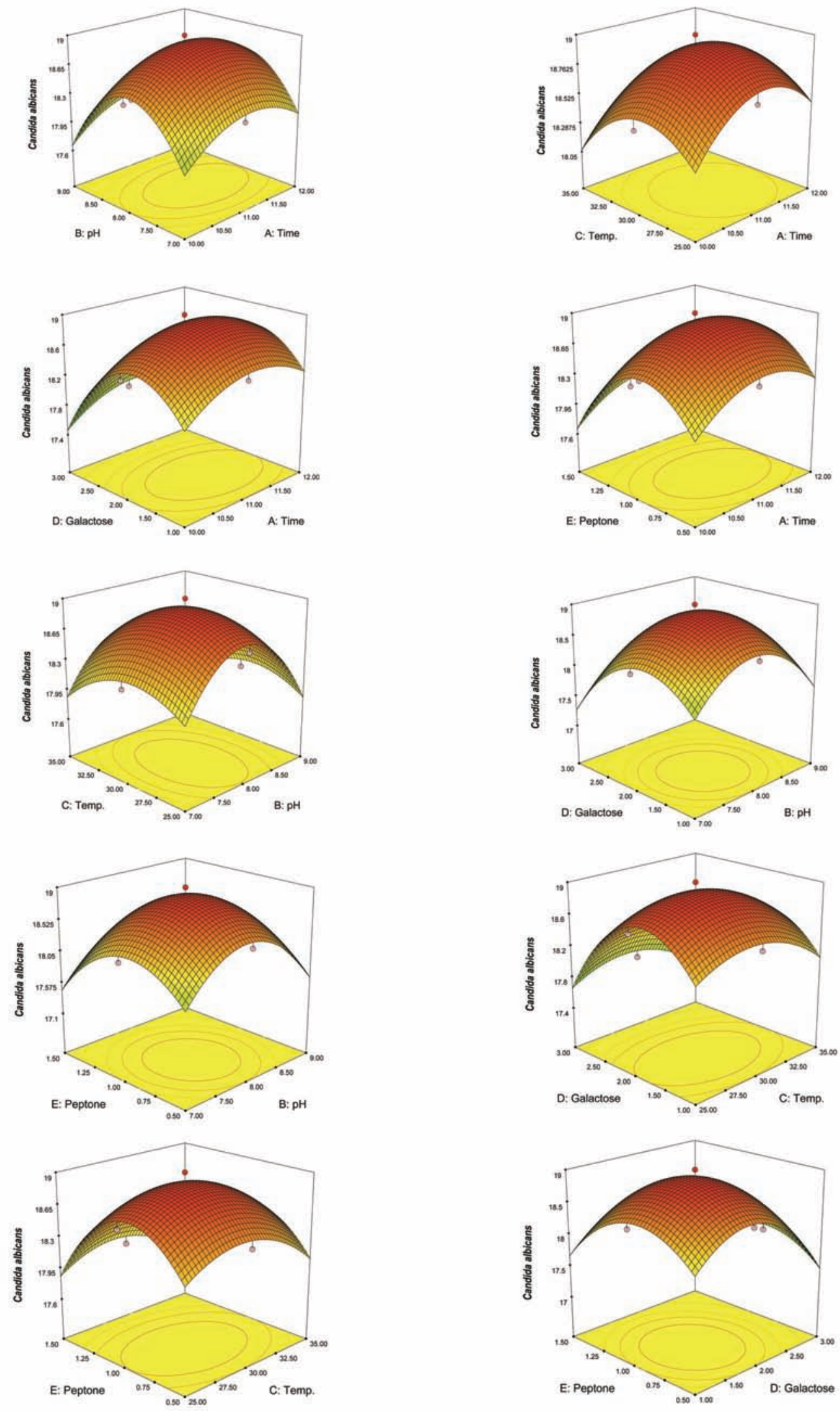

Figure 5: 3D plots showing interactive effects of selective variables on zone of Inhibition $(\mathrm{mm})$ of the bioactive compound production by VSM 25 against Candida albicans. 


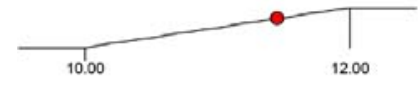

Time $=11.46$

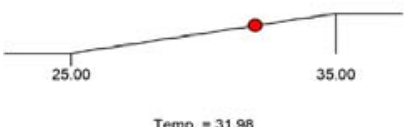

Temp, $\mathbf{= 3 1 . 9 8}$

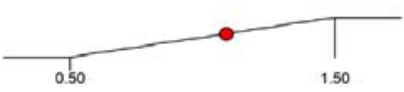

Peptone $=1.09$

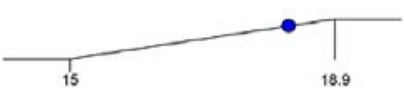

A. favis $=18.2249$

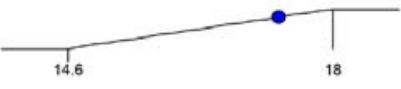

F. solan $i=17.3109$

Desirability $=0.728$

Figure 6: Response optimization plots of all the five variables and responses.

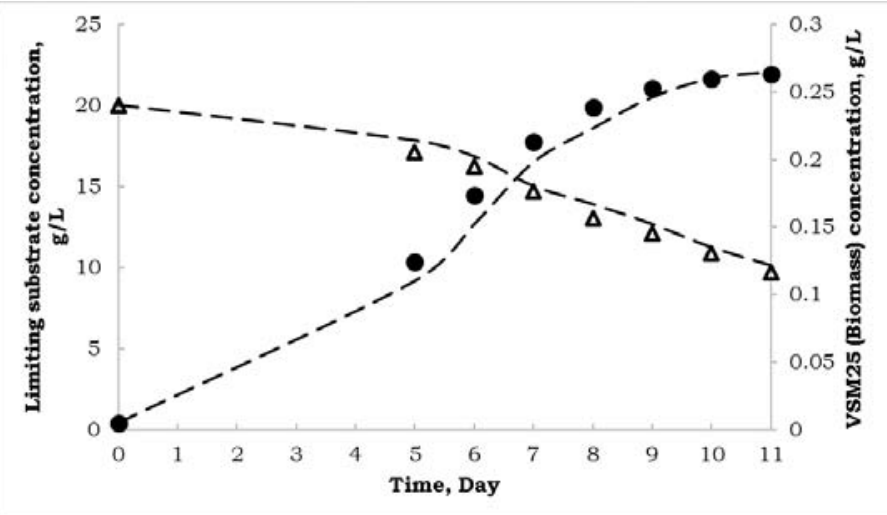

Figure 7: Experimental and model predicted kinetics of biomass, substrate utilization. •- Experimental Biomass concentration (g/L), $\Delta$ - Experimental substrate concentration (g/L), ----- Model predicted values (in each case).

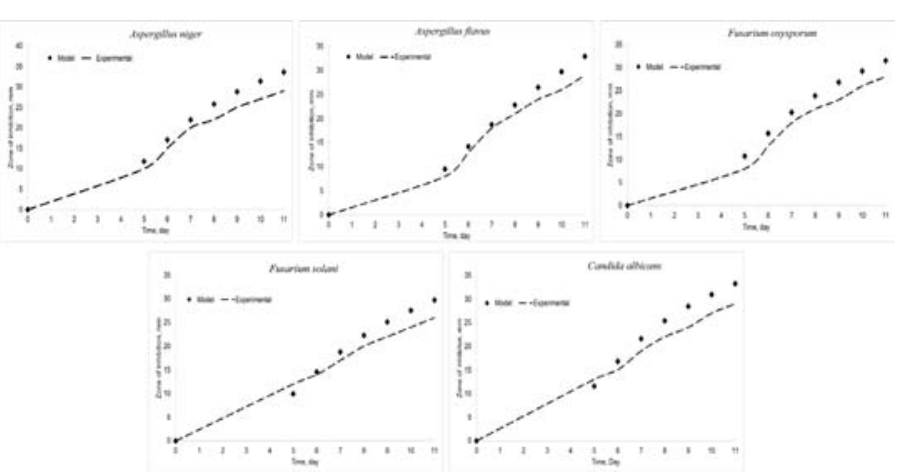

Figure 8: Comparison of experimental and model predicted kinetics of zone of inhibition. the optimization process for the antifungal metabolite production by S.arabica VSM 25. All the 50 experiments were accomplished in randomized run order to determine the interactive effects of process variables, their effect against the responses (Inhibition of the growth of the pathogenic fungi was represented in $\mathrm{mm}$ ). The optimization of bioactive metabolite production parameters was generated and the predicted values of the yield were well consistent with experimental values. The statistical significance of the model is determined by the $p$-value and the $p$ value of all the five response was found to be $<0.0001 .{ }^{27}$ The model is said to be highly significant if the value of $p$ is $<0.05^{28}$. Regression analysis of ANOVA showed a good fit of the experimental data of each response through second order polynomial equation. Coefficient determination $\left(R^{2}\right)$ indicates the proportion of the total variability of the model explained and suggested that the model is a good fit. The suggested $R^{2}$ value for a good fit model should be close to 1 or at least $0.80 .{ }^{29}$ The value $\left(R^{2}\right)$ of the 5 responses was $>0.9$ (Table 4 ) which indicate that model is a good fit. But $R^{2}$ increases with factors added which are not significant. ${ }^{30}$ Hence adjusted $R^{2}$ is used for model adequacy, since adjusted $R^{2}$ adjusts for the models' size. ${ }^{25}$ The insignificant factors added to the model are decreased by the adjusted $R^{2} .^{30}$ The adjusted $\left(R^{2}\right)$ value of all the responses was $>0.9$ which indicate the model to be a very good fit. Signal to noise ratio is measured by adequate precession and values greater than four are desirable for the model to be significant. Coefficient variation $(\mathrm{CV})$ is the standard deviation expressed in terms of percentage of the mean and should be less than $10 \%{ }^{25}$ Adequate precession and Coefficient variation of the five responses in the present study was found to be greater than four and less than $10 \%$.

$3 \mathrm{D}$ plots obtained showed the interactive effects of the process variables on the bioactive metabolite production and its effect against the five responses. All the five variables studied had significant impact on the bioactive metabolite production by VSM 25. ${ }^{25}$ The optimum values of time of incubation, $\mathrm{pH}$, temperature and concentration of galactose and peptone was found to be 11 days, $30^{\circ} \mathrm{C}$, pH 8 and concentration of galactose $2 \%$ and peptone $1 \%$. The recorded zones of inhibition (mm) against the five responses included $20.8 \mathrm{~mm}$ for Aspergillus niger, $18.9 \mathrm{~mm}$ for Aspergillus flavus, $20 \mathrm{~mm}$ for Fusarium oxysporum, $18 \mathrm{~mm}$ for Fusarium solani and $19 \mathrm{~mm}$ for Candida albicans by the bioactive metabolite produced by VSM-25.

The estimated kinetic parameters for the S.arabica VSM 25 growth limiting substrate utilization and bioactive metabolite production (in terms of inhibition zones measured for 5 fungal pathogens) showed good regression squares with good fit. Therefore, the unstructured models furnished a better approximation of kinetic profiles of bioactive metabolite production by S.arabica VSM 25 in submerged shake flask fermentations. Subsequently, over all findings carry the insights of the crucial information for large scale production of the antimycotic natural metabolites from novel VSM-25 strain that may be used to find new compounds for the clinical utility.

\section{CONCLUSION}

A novel actinomycete VSM-25 was able to grow and synthesize the bioactive metabolite under a wide range of experimental conditions. RSM based experimental study determine the significant parameters and their interactions affecting the optimization process. Optimization of bioactive metabolite production parameters were designed by CCD of RSM, and the predicted values are in agreement with experimental values. High values of $R^{2}$, adjusted $R^{2}$, predicted $R^{2}$ and adequate precession along with low values of the coefficient of variation concluded that the models for responses fit the experimental data adequately. The unstructured models furnished a better approximation of kinetic profiles 
of bioactive metabolite production by S. arabica VSM 25 in submerged shake flask fermentations.

\section{ACKNOWLEDGEMENT}

The first author U.K.M is grateful to University grants commission (U.G.C), New Delhi, Government of India, for providing financial assistance in the form of fellowship to carry out this work.

\section{CONFLICTS OF INTEREST}

All authors have none to declare.

\section{ABBREVIATION USED}

RSM: Response Surface Methodology; ANOVA: Analysis of Variance.

\section{REFERENCES}

1. Bredholdt H, Galatenko OA, Engelhardt K, Fjærvik E, Terekhova LP, et al. Rare actinomycete bacteria from the shallow water sediments of the Trondheim fjord, Norway: isolation, diversity and biological activity. Environmental microbiology. 2007;9(11):2756-64. https://doi.org/10.1111/j.1462-2920.2007.01387.x; PMid:17922759

2. Souagui Y, Tritsch D, Grosdemange-Billiard C, Kecha M. Optimization of antifungal production by an alkaliphilic and halotolerant actinomycete, Streptomyces sp. SY-BS5, using response surface methodology. Journal de Mycologie Médicale/ Journal of Medical Mycology. 2015;25(2):108-15. https://doi.org/10.1016/j.mycmed.2014.12.004; PMid:25703134.

3. Singh LS, Mazumder S, Bora TC. Optimisation of process parameters for growth and bioactive metabolite produced by a salt-tolerant and alkaliphilic actinomycete, Streptomyces tanashiensis strain A2D. Journal de Mycologie Médicale/Journal of Medical Mycology. 2009;19(4):225-33. https://doi. org/10.1016/j.mycmed.2009.07.006.

4. Nawaz H, Shad MA, Abbasi ST. Extraction Optimization of Phenolic Antioxidants from microwave treated Nelumbo nucifera Seed Flour. Free Radicals and Antioxidants. 2017;7(1):63. https://doi.org/10.5530/fra.2017.1.10.

5. Ilaiyaraja N, Likhith KR, Babu GS, Khanum F. Optimisation of extraction of bioactive compounds from Feronia limonia (wood apple) fruit using response surface methodology (RSM). Food chemistry. 2015;173:348-54. https://doi. org/10.1016/j.foodchem.2014.10.035; PMid:25466032.

6. Alberti A, Zielinski AA, Zardo DM, Demiate IM, Nogueira A, et al . Optimisation of the extraction of phenolic compounds from apples using response surface methodology. Food chemistry. 2014;149:151-8. https://doi.org/10.1016/j.foodchem.2013.10.086; PMid:24295689.

7. Sheng ZL, Wan PF, Dong CL, Li YH. Optimization of total flavonoids content extracted from Flos Populi using response surface methodology. Industrial Crops and Products. 2013;43:778-86. https://doi.org/10.1016/j.indcrop.2012.08.020.

8. Liu Y, Wei S, Liao M. Optimization of ultrasonic extraction of phenolic compounds from Euryale ferox seed shells using response surface methodology. Industrial Crops and products. 2013;49:837-43. https://doi.org/10.1016/..indcrop.2013.07.023.

9. Kontogiannopoulos KN, Patsios SI, Karabelas AJ. Tartaric acid recovery from winery lees using cation exchange resin: Optimization by Response Surface Methodology. Separation and Purification Technology. 2016;165:32-41. https:// doi.org/10.1016/i.seppur.2016.03.040.

10. Sheng ZL, Wan PF, Dong CL, Li YH. Optimization of total flavonoids content extracted from Flos Populi using response surface methodology. Industrial Crops and Products. 2013;43:778-86. https://doi.org/10.1016/j.indcrop.2012.08.020.

11. Luedeking R, Piret EL. Transient and steady states in continuous fermentaion. Theory and experiment. Journal of biochemical and microbiological technology and engineering. 1959;1 (4):431-59. https://doi.org/10.1002/jbmte.390010408.

12. Rogers PL, Bramall L, McDonald IJ. Kinetic analysis of batch and continuous culture of Streptococcus cremoris HP. Canadian journal of microbiology. 1978;24(4):372-80. https://doi.org/10.1139/m78-063; PMid:346186.

13. Leh MB, Charles M. The effect of whey protein hydrolyzate average molecular weight on the lactic acid fermentation. Journal of Industrial Microbiology \& Biotechnology. 1989;4(1):77-80. https://doi.org/10.1007/BF01569697.

14. Amrane A, PrigentY. Lactic acid production from lactose in batch culture: analysis of the data with the help of a mathematical model; relevance for nitrogen source and preculture assessment. Applied microbiology and biotechnology. 1994;40(5):644-9. https://doi.org/10.1007/BF00173322

15. Dutta SK, Mukherjee A, Chakraborty P. Effect of product inhibition on lactic acid fermentation: simulation and modelling. Applied microbiology and biotechnology. 1996;46(4):410-3. https://doi.org/10.1007/BF00166238; https://doi.org/10.1007/ s002530050838.

16. Boonmee M, Leksawasdi N, Bridge W, Rogers PL. Batch and continuous culture of Lactococcus lactis NZ133: experimental data and model development. Biochemical engineering journal. 2003;14(2):127-35. https://doi.org/10.1016/ S1369-703X(02)00171-7.

17. Sinclair CG, Kristiansen B, Bu'Lock JD. Fermentation kinetics and modelling. Open University Press; 1987.

18. Znad H, Blažej M, Báleš V, Markoš J. A kinetic model for gluconic acid production by Aspergillus niger. name Chemical Papers. 2004;58(1):23.

19. Rajendran A, Thangavelu V. Evaluation of various unstructured kinetic models for the production of protease by Bacillus sphaericus MTTC511. Engineering in Life sciences. 2008;8(2):179-85. https://doi.org/10.1002/elsc.200700033.

20. Hayakawa $M$, Nonomura $H$. A new method for the intensive isolation of actinomycetes from soil. Journal of the Japanese Society of Actinomycetes. 1989;3(2):95-104. https://doi.org/10.3209/saj.3_95.

21. Martins FS, da Conceição EC. Evaluation of extraction method on the chemical composition in Apeiba tibourbou Aubl's extracts. Pharmacognosy magazine. 2015;11(42):368. https://doi.org/10.4103/0973-1296.153091; PMid:25829777 PMCid:PMC4378136.

22. Md. Shamsir Alam, Zoheir A. Damanhouri, Aftab Ahmad, Lubna Abidin, Mohd Amir, Mohd Aqil, Shah Alam Khan, Mohd Mujeeb. Development of response surface methodology for optimization of extraction parameters and quantitative estimation of embelin from Embelia ribes Burm by high performance liquid chromatography. Phcog Mag 2015: 11: 166-172. https://doi.org/10.4103/09731296.157722; PMid:26109763 PMCid:PMC4461957.

23. Myers RH, Montgomery DC, Anderson-Cook CM. Response Surface Methodology: Process and Product Optimization Using Designed Experiments. Wiley Inc; 2011

24. Cheng KC, Demirci A, Catchmark JM, Puri VM. Modeling of pullulan fermentation by using a color variant strain of Aureobasidium pullulans. Journal of food engineering. 2010;98(3):353-9. https://doi.org/10.1016/j.jfoodeng.2010.01.011.

25. Li HX, Lu ZM, Geng Y, Gong JS, Zhang XJ, et al. Efficient production of bioactive metabolites from Antrodia camphorata ATCC 200183 by asexual reproductionbased repeated batch fermentation. Bioresource technology. 2015;194:334-43. https://doi.org/10.1016/i.biortech.2015.06.144; PMid:26210148.

26. Leroy $\mathrm{F}$, de Vuyst $\mathrm{L}$. Temperature and $\mathrm{pH}$ conditions that prevail during fermentation of sausages are optimal for production of the antilisterial bacteriocin sakacin $\mathrm{K}$. Applied and Environmental Microbiology. 1999;65(3):974-81.PMid:10049850 PMCid:PMC91131.

7. Luedeking R, Piret EL. A kinetic study of the lactic acid fermentation. Batch process at controlled pH. Biotechnol Bioeng. 2000; 67: 636-44. https://doi. org/10.1002/(SICI)1097-0290(20000320)67:6<636::AID-BIT3>3.0.CO;2-U.

28. Yi XS, Shi WX, Yu SL, Li XH, Sun N, He C. Factorial design applied to flux decline of anionic polyacrylamide removal from water by modified polyvinylidene fluoride ultrafiltration membranes. Desalination. 2011 Jul 1:274(1):7-12. https://doi. org/10.1016/j.desal.2010.10.019. ss

29. Chandra P, Arora DS. Antioxidant Potential of Penicillium citrinum and its Optimization through Different Statistical Approaches. Free Radicals and Antioxidants. 2011;1(4):48-55. https://doi.org/10.5530/ax.2011.4.8.

30. Abdel-Ghani NT, Hegazy AK, El-Chaghaby GA, Lima EC. Factorial experimental design for biosorption of iron and zinc using Typha domingensis phytomass. Desalination. 2009;249(1):343-7. https://doi.org/10.1016/j.desal.2009.02.065.

Article History: Submission Date : 21-02-2017; Revised Date : 04-05-2017; Acceptance Date : 29-05-2017.

Cite this article: Managamuri U, Vijayalakshmi M, Poda S, Ganduri VSRK, Rajulapati SB. Optimization of Operating Conditions for the Production of Enhanced Antifungal Metabolites from Streptomonospora arabica VSM 25 by Full Factorial Design. J Young Pharm. 2017;9(3):399-409. 